\title{
The Commodification of Humanism: Methods, Marketing, and Morals of a Postmodern Shift in the Philosophy of Medicine
}

\section{Ericka Iny ${ }^{1}$ \\ ${ }^{1}$ Faculty of Medicine, McGill University, Montréal, Québec, Canada \\ Correspondence \\ Ericka Iny \\ Email: ericka.iny@mail.mcgill.ca \\ Publication Date \\ March 8, 2021 \\ MJM 2021 (19) 10 \\ https://doi.org/10.26443/mjm.v19i1.832 \\ McGill \\ Journal of Medicine}

www.mjmmed.com

\section{c) (i) (2)}

This work is licensed under a Creative Commons BY-NC-SA 4.0 International License.

\begin{abstract}
Consideration of the history of medicine reveals a postmodern shift in the philosophy of medicine, one that arguably strays from its humanist foundations. Though often attributed to Sir William Osler's contributions, the modernization of medicine extends beyond his influence, as well as beyond his time. Peaking in the mid-1900s, the paradigm shift in the philosophy of medicine continues to compel a certain dichotomy between humanism and medicine today. Despite being historically intertwined, medicine distances itself from humanism amidst the institutionalization, depersonalization, and monetization of the medical field. Notably, the commodification of medicine entails three central themes: methods, marketing, and morals.
\end{abstract}

\section{KEYWORDS}

Commodification of medicine, Humanism in medicine, Sir William Osler

\section{1 | INTRODUCTION}

Bearing witness to the results of progress in the medical field during the 20th century and into the 21st century, the practice of medicine is arguably at its peak. The contributions of Sir William Osler towards modernizing the medical curriculum through the implementation of bedside clinical teaching at the turn of the 20th century, followed by the predominant emphasis on humanism in medical philosophy thereafter, permanently altered the course of medicine. (1) Osler advanced the scientific basis of medicine whilst recognizing that an interaction between both science and humanism was imperative, (2) and that maintaining a dichotomy between the two was neither feasible nor beneficial. Yet, Osler understood that humanism could easily be lost amidst scientific progress, and his teachings tend to emphasize this. Indeed, his adamance towards prioritizing the patient 
in medical practice might now be viewed as an overt awareness, and perhaps a warning, concerning the future of medicine.

Despite the apparent success of medicine, the changes that Osler initiated were developed beyond his intentions. What began as a culmination of patientcentered teaching and treatment soon evolved into a sometimes depersonalized approach reliant on a hierarchical systemization within hospitals. Among other factors, this brought about an unforeseen deviation from Osler's widely-adopted humanist narrative in which he insisted that "it is much more important to know what sort of a patient has a disease than what sort of a disease a patient has". (3)

While Osler was seen as a pioneer of innovation in his time, he is now perceived by medical students as the embodiment of an ideal physician - one that demonstrates profound medical knowledge and maintains a humanist attitude. (2) Yet, this idealization acknowledges that the embodiment of both science and humanism is not presently a reality. An understanding of the medical field today requires a consideration of both the history and philosophy of medicine in the 20th century.

The postmodern era, defined primarily by the $1960 \mathrm{~s}$, (4) saw the emergence of new technologies, a redefinition of the norms in medical practice, a distancing from Hippocratic traditions, and ultimately, the commodification of medicine. Indeed, an exploration of the medical field following the scientific and technological revolution of the mid-1900s reveals a shift in the philosophy of medicine - one that strays from the very humanism upon which medicine was founded. With the rise of evidencebased medicine amidst new technologies, the specialization and institutionalization of doctors, and a shift in the values of medicine towards depersonalization and monetization, the commodification of medicine entails three central themes: methods, marketing, and morals.

\section{2 | METHODS}

The scientific and technological revolution of the 20th century gave rise to an explosion of scientific knowl- edge, an increase in communications technology, and a series of innovations that would jumpstart progress in the realms of physics, chemistry, and biology. Following the Second World War specifically, the sudden flux of scientific technologies and discoveries permitted nations to adopt a sentiment of modernization, (5) and most importantly, improvement. Characterized by a decreased prevalence of bacterial diseases thanks to the development of antibiotics, as well as the elimination of polio and smallpox as a result of effective vaccines, the medical field was among those revolutionized. (5) Laboratory technologies permitted medical advances beyond the hospital's walls, while the introduction of computerized tomography, magnetic resonance imaging, and radiation therapy improved treatment and diagnosis within the hospital. Yet, along with this development of new technologies came a certain dependence on these innovations as the only means of furthering medicine. For instance, between 1997 and 2006 in Washington State alone, 377,048 patients underwent 4.9 million diagnostic tests with the uses of computed tomography and magnetic resonance imaging doubling and tripling, respectively. (6) In part due to the modern widespread availability of advanced technologies, the use of technology in hospital settings is now unprecedented. Yet, while the use of technologies has increased, there has not been an associated change in the frequency of illness - which could suggest an overuse of diagnostic medical imaging. (6) The use of diagnostic technology "defensively" - as a means of eliminating anxiety in the face of ambiguity - has implicitly created an obligation to utilize technology, sometimes regardless of actual need. (7) Indeed, this trend has not only contributed to a rapid growth in medical costs, but also an increase in radiation exposure - one that has been suspected to contribute to cancer. (7) Ultimately, neither the increased costs nor the increased radiation exposure prioritizes the patient's wellbeing.

Albeit providing the option of reliable diagnostic testing, technological advancements are often overused and have arguably eroded communication within hospitals. Despite being enforced as ways to reduce human error and facilitate documentation, electronic health records 
(EHRs) and health information exchanges (HIEs) have been associated with a weakening of physician's abilities to make informed clinical decisions. (8) Similarly, new technologies have been linked to a decreased willingness to learn and retain bases of medical knowledge because they are readily accessible online. This phenomenon is reflected in the $12 \%$ decrease found in the overall pass rate of the Maintenance of Certification (MOC) internal medicine board exam from 2009 to 2013. (8) Most importantly, studies have found that the standardized use of EHRs and HIEs by healthcare professionals can impede doctor-patient communication. (9) While there have undoubtedly been doctors who perform excessive documentation on paper charts, the implementation of EHRs and HIEs have normalized an emphasis on record taking, with many doctors admitting to the use of "cut-and-paste boilerplate text" in patient charts. (10) Pressured to fill endless boxes with patient information, physicians may inadvertently adopt a nearly robotic interrogation of patients, rather than an empathetic conversation. With physicians' eyes glued to the screen, patients may feel a lack of human connection and care. The addition of a screen between the doctor and the patient has not only added a literal barrier, but also a symbolic gap in communication and understanding.

Beyond the devolution of individual interactions between physicians and patients following the postmodern era, the systemic treatment of patients has also experienced a paradigm shift - one from clinical judgement to evidence-based medicine (EBM). (11) Formally introduced to medical literature in 1992 by Gordon Guyatt at McMaster University, (12) EBM was presented as a method which "de-emphasizes intuition, unsystematic clinical experience, and pathophysiologic rationale as sufficient grounds for clinical decision making and stresses the examination of evidence from clinical research". (11) With only two published articles referring to EBM in 1992, (13) and over 20,000 in 2015, (14) EBM soon became one of the milestones that shaped the medical field. (15) Despite attempts to redefine current EBM as a combination of both research evidence and clinical experience, it is the initial "de-emphasiz[ing] intuition" which conflicts physicians today, regardless of agreed-upon definitions. Opponents of EBM argue that its approach to scientific knowledge prioritizes internal validity, which consequently promotes the explanatory randomized controlled trial (RCT) as a means of standardizing medical treatment. (14) While evidence from RCTs has proven effective for single disease conditions, it largely fails to address multimorbidity and social determinants of health. (14) Indeed, with the focus of clinical trials on entire populations rather than individuals, (5) the threat of EBM lies in its imposition of uniform instructions instead of care designed for the needs, context, and predisposed risks of each patient. (16).

\section{3 | MARKETING}

Concomitant with the rise of EBM resulting from a new emphasis on science in medicine, and science as medicine, there came about a new image of physicians-that of the specialized technologist. (17) Amidst an environment of advanced technology and evidencebased approaches, the subjective patient was often bypassed for undisputable images from medical instruments - disregarding unnecessary costs that might be avoided through patient interaction. Meanwhile, the financial approach to medicine, that of commodification, is arguably the basis of an ever-growing depersonalization culture. For example, in the United States approximately $25 \%$ of total healthcare spending is deemed wasted on factors including over-treatment. (18) Moreover, while nearly $18 \%$ of the gross domestic product goes towards health care in the United States, (18) 28 million Americans remain uninsured. (19) As such, there exist immense disparities in access to - and quality of healthcare.

Following the mobilization of social programs during World War II, employer-financed private health insurance was adopted. (17) Whereas most other developed countries opted for a social insurance model based on sharing the cost of sickness, (17) the United States fared with a business model. By the 1970s, most politicians were in full support of privatization and deregulation, 
(20) a decision that would distinguish the state of the American healthcare system going into the 21st century. The expansion of healthcare from the private sector into the public sphere was introduced as neoliberalism. (21) With a restructured healthcare system emphasizing free market capitalism, individuals were granted the choice of care rather than equitable access to care. (21) However, this choice could be perceived as more of a burden for those without the knowledge or the funds to distinguish "good" healthcare from "bad" healthcare. (21) Market theory in itself constitutes that the consumer is aware of their needs and holds bargaining power over different prices. (17) While transferable to industrialization where there exists a legitimate choice to consume or not, market theory does not hold up in the context of medicine where patients do not choose to be ill and often are not familiar with their diagnostic options. (17) Business ethics in medicine condone unequal care based on the ability, or lack thereof, to afford treatment. (22) With an inflation of $176 \%$ in the average cost of emergency room entry (excluding treatment) from 2008 to 2017 in the United States, there is little evidence of an improvement in the quality of care provided to support this increase. (21)

While the privatization of medical care in the United States is an overtly tangible example of the commodification of medicine, there exist subtler, yet nonetheless prevalent, presentations in hospitals worldwide. When one thinks of physicians today, the range of different specialties comes to mind, as they are so ingrained in medical culture that we do not stop to question it. However, the over-specialization of physicians is integral to the commodification of medicine, as it greatly contributed to the standardization of care and thus a distancing from patient-oriented care. Initiated due to a combination of increasing medical knowledge as well as economic incentives, specialization was normalized, and the family physician that patients trusted was lost. (23) The limitation of one's practice to a single area, along with rising patient distrust, essentially facilitated the transition into standardized care. Amidst an increasing understanding of the responsibility held by physicians, and the accountability brought about by misdiag- noses, came the rise of defensive medicine - an overuse and reliance on tests, procedures, and prescriptions to treat patients. (24) The progression into standardization led to continuity of care becoming scarce and paved the way for managed care organizations. Instead of treatment by a single physician, corporations were perceived as the "doctor" who would provide someone to deliver the commodity of medicine. (22) Indeed, the institutionalization of corporate medicine decreased personalized patient-physician relationships and eliminated any remnants of the idolized "top-hatted nineteenthcentury physician." (23) Nowadays, the hierarchical systemization of healthcare professionals implicitly emulates an assembly-line approach to medicine. (25) Ultimately, these changes make it difficult to insist that humanism and altruism are at the forefront of 21 st century medicine.

\section{4 | MORALS}

Dating back to 2600 BC, (26) medicine as a concept, profession, and virtue has undergone a lengthy evolution. This is particularly true with respect to the patientphysician relationship, the philosophy of medicine, and the presence of humanism - or lack thereof. Notably, the formal founding of modern medicine has been credited to Hippocrates, due largely to the prevalence of his Hippocratic Principles and Oath outlining the pillars of physician responsibility. (27) Referred to as "the techne of iatrike", the earliest formal account of medicine concerned itself with the health of the body and held intricate relations with ritual and philosophy, which centered around the soul. (28) Inaugurated as a "techne"an art, (28) the ancient Greek practice of "iatrike" held connotations (in both science and art) distinct from later definitions of medicine. Though, within this art of healing, there exists speculation that Hippocrates aimed to establish medicine as a scientific domain, thereby denying ties to philosophy. (29) Medicine, being nested in philosophy, was initially based on the pretext that "doctors" held curative powers as wizards and clergy. (25) Concomitantly, the origins of philosophy have also 
been said to be rooted in the methodology and worldview of medicine. (25) To this day, medicine and philosophy remain intrinsically linked, whether that be implicitly or explicitly. Upon further inspection of Hippocrates' supposed desire to dichotomize medicine and philosophy, (29) it is evident that by virtue of distancing from philosophy in medicine, a philosophy of medicine emerged. Integral to the early philosophy of medicine, the notion of humanism guided the responsibilities of the physician. Only formally coined by physician Scribonius Largus in the first century $A D$, humanitas was intended as the philosophical foundation for the role of the physician, and the love of mankind. (30) The centrality of humanism within the philosophy of medicine gave rise to the depiction of physicians as "benign, benevolent, all-knowing authoritarian" figures. (30) Amidst a public lack of medical knowledge, however, patient rights were absent from Hippocratic ethics, (31) which dealt solely with the concepts of benefit and duty in a physician-centered model of the patient-physician relationship. (32)

Progressing well into the Middle Ages, Christian religion heavily influenced the Western concept of medicine, (33) thereby allocating a moral authority based on Hippocratic values - to physicians. Up until the mid-17th century, patient passivity imposed by the authority of physicians was left relatively undisputed. Moral authority was only formally replaced by legal authority in 1690 with the publication of John Locke's Two Treatises on Civil Government, which proposed a theory of human rights and subsequently altered the patientphysician relationship. (33) Translated to the context of medicine, Locke's philosophy presented the formerly physician-centered model as a contract for service between two autonomous individuals. (30) Entering the Oslerian era of the early 20th century, this model persisted, withstanding criticism associated with the progressive loss of the benevolent physician. Representing an embodiment of the humanist qualities ingrained in the philosophy of medicine, Osler advocated for the maintenance of a patient-centered model in medical practice. (1) Efforts included a modernization of the medical curriculum to include bedside teachings, as well as a strong opposition to the dichotomization of science and humanism. (2) Despite the amplification of Osler's contributions towards maintaining a humanist philosophy of medicine, his then-revolutionizing perspective in the medical field dissipated during the very next revolution.

The scientific and technological revolution of the mid-20th century enabled a paradigm shift in the philosophy and practice of medicine. Hippocratic traditions, which had prevailed until the 1960s, were suddenly under question. (33) This was in part due to rising mass demonstrations and social upheavals in the United States, (33) as well as the swift global prevalence of new technologies. Indeed, public dismay emerged from a predominant distrust towards institutions - including that of medicine. While previous societies had been immobilized in a spectator's role on the subject of national decision-making, (33) a radicalization in societal participation permitted widespread advocacy for the traditional patient who had assumed a passive role in medical practice. (32) Newly informed on the basics of medicine and their fundamental rights, patients adopted the role of consumers in a field focused on promoting "customer satisfaction". (34) The commercialization and institutionalization of medicine, facilitated by a rise in technologies and standardization in practices, permitted a paradigm shift in the philosophy of medicine: the commodification of the patient-physician relationship as a business model. With medical knowledge as proprietary ownership, (30) the business model is based on the understanding that medical practices are analogous to a transaction between a customer (patient) and a provider (physician). (32) Indeed, this model can be categorized as patient-centered as it challenges the physician's unilateral authority and permits the patient to 'shop' for a physician who satisfies their needs. (32) However, within a model comprising savvy providers and wary consumers, there exists a foundation built on distrust. (32) Certainly, the presence of distrust in medicine is seemingly counterintuitive, yet it is more so exemplified within a model where medicine exists as a commodity analogous to quotidian purchases. Along with said commodification, the postmodern era gave rise to the ques- 
tion of depersonalization in the patient-physician relationship. The increase in medical perspectives regarding the patient not as a person in need, but rather as a case, an ailing organ, or a part in an assembly line, (25) have heralded the loss of humanism. Effectively, a philosophy based on commodification and depersonalization cannot claim reasonable ties to humanism.

\section{5 | CONCLUSION}

Despite undoubted progress in the medical field, there continues to exist immense discrepancies in the access to - and quality of - medicine worldwide. Further, contextual differences invariably remain in what "good" medicine is perceived to be. In acknowledging that these factors may neither have been considered nor relevant in Osler's time, it is not appropriate to adopt a former approach that has become incompatible with the complex reality of 21st century medicine. However, given the lasting idealization of Osler in the minds of ambitious medical students and accomplished physicians, the desire to revolutionize the medical field is not uncommon. Certainly, the last century has brought about exponential and continuous progress in medical technologies, yet it has nonetheless predominantly overlooked progress in the medical perspective. Consequently, the philosophy of medicine has strayed from its humanist foundations. Indeed, a complete understanding of modern criticism requires an exploration of the history of medicine - primarily ensuing the scientific and technological revolution of the mid-20th century. Consideration of the methods, marketing, and morals of the medical field, through both individual physicians and healthcare systems, reveals a paradigm shift in the philosophy of medicine - one which institutionalizes and normalizes practices lacking a humanist approach, and sequentially risks neglecting patients. Amidst prevailing antihumanist trends revealed in present politics and prejudices, a mandate to uphold humanism in medicine ultimately extends beyond hospital walls. (35) Healthcare professionals are not only challenged with restoring humanism in the medical field itself, but concomitantly serving as models to confront a gradually dehumanizing society.

\section{ACKNOWLEDGEMENTS}

The author received no financial support for the research, authorship, or publication of this article.

\section{REFERENCES}

1. Geyman JP. The Oslerian tradition and changing medical education: a reappraisal. West J Med [Internet]. 1983 [cited 2020 Sep 14];138(6):884-8. Available from NCBI: https://pubmed.ncbi.nlm.nih.gov/6351442/

2. Craxì L, Giardina S, Spagnolo AG. A return to humane medicine: Osler's legacy. Infez Med [Internet]. 2017 [cited 2020 Sep 14];25(3):292-7. Available from NCBI: https://pubmed.ncbi.nlm.nih.gov/28956551/

3. Osler W. Aequanimitas and other addresses. San Francisco (CA): Internet Archive; 2008 (Original work published 1904). Available from: https://archive.org/stream/aequanimitas00osle?ref=ol

4. Gottschalk S. Uncomfortably numb: countercultural impulses in the Postmodern era. Symbolic Interaction [Internet]. 1993 [cited 2020 Jul 3];16(4):351-78. doi:10.1525/si.1993.16.4.351

5. Weatherall D, Greenwood B, Chee HL, et al. Jamison DT, Breman JG, Measham AR, et al., editors. Science and technology for disease control: past, present, and future. Disease Control Priorities in Developing Countries, 2nd edition. Washington (DC): The International Bank for Reconstruction and Development / The World Bank; 2006. Available from: https://www.ncbi.nlm.nih.gov/books/NBK11740/

6. Smith-Bindman R, Miglioretti DL, Larson EB. Rising use of diagnostic medical imaging in a large integrated health system. Health Aff (Millwood) [Internet]. 2008 [cited 2020 Aug 22];27(6):1491502. doi:10.1377/hlthaff.27.6.1491

7. Goodman RL. Health care technology and medical education: putting physical diagnosis in its proper place. Acad Med [Internet]. 2010 [cited 2020 Aug 30];85(6):945-6. doi:10.1097/ACM.0b013e3181dbb55b

8. NEJM Knowledge+ Team [Internet]. Massachusetts: Massachusetts Medical Society; c2020. ABIM pass rates: behind the declines; 2014 Oct 16 [cited 2020 Aug 31]. Available from: https://knowledgeplus.nejm.org/blog/abim-pass-rates-behind- declines/

9. Cummings CL. Communication in the era of COWs: technology and the physician- patient-parent relationship. Pediatrics [Internet]. 2013 [cited 2020 Aug 31];131(3):401-3. doi:10.1542/peds.20123200

10. Hoff T. Deskilling and adaptation among primary care 
physicians using two work innovations. Health Care Manage Rev [Internet]. 2011 [cited 2020 Aug 31];36(4):338-48. doi:10.1097/HMR.0b013e31821826a1

11. Guyatt G, Cairns J, Churchill D, et al. Evidence-based medicine: a new approach to teaching the practice of medicine. JAMA [Internet]. 1992 [cited 2020 Sep 1];268(17):2420-5. doi:10.1001/jama.1992.03490170092032

12. Masic I, Miokovic M, Muhamedagic B. Evidence based medicine - new approaches and challenges. Acta Inform Med [Internet]. 2008 [cited 2020 Sep 1];16(4):219-25. doi:10.5455/aim.2008.16.219225

13. Zimerman AL. Evidence-based medicine: a short history of a modern medical movement. Virtual Mentor [Internet]. 2013 [cited 2020 Aug 31];15(1):71-6. doi:10.1001/virtualmentor.2013.15.1.mhst1-1301

14. Fernandez A, Sturmberg J, Lukersmith S, Madden R, Torkfar G, Colagiuri R, et al. Evidence-based medicine: is it a bridge too far? Health Res Policy Syst [Internet]. 2015 [cited 2020 Sep 4];13:66. doi:10.1186/s12961-015-0057-0

15. Thoma A, Eaves FF, 3rd. A brief history of evidence-based medicine (EBM) and the contributions of Dr David Sackett. Aesthet Surg J [Internet]. 2015 [cited 2020 Sep 4];35(8):NP261-3. doi:10.1093/asj/sjv130

16. Chung KC, Ram AN. Evidence-based medicine: the fourth revolution in American medicine? Plast Reconstr Surg [Internet]. 2009 [cited 2020 Sep 4];123(1):389-98. doi:10.1097/PRS.0b013e3181934742

17. Lown B. The commodification of health care. PNHP [Internet]. 2007 [cited 2020 Sep 8];40-44. Available from: http://pnhp.org/PDF_files/spring2007newsletter_lown.pdf

18. Shrank WH, Rogstad TL, Parekh N. Waste in the US health care system: estimated costs and potential for savings. JAMA [Internet]. 2019 [cited 2020 Sep 13];322(15):1501-9. doi:10.1001/jama.2019.13978

19. Woolhandler S, Himmelstein DU. Intersecting U.S. epidemics: COVID-19 and lack of health insurance. Ann Intern Med [Internet]. 2020 [cited 2020 Sep 12];173(1):63- 4. doi:10.7326/M20-1491

20. Ameringer $\mathrm{C}$. The health care revolution: from medical monopoly to market competition [Internet]. California: University of California Press; 2006 [cited 2020 Sep 8]. Available from Project MUSE: https://muse.jhu.edu/book/25444

21. Ratna HN. Medical neoliberalism and the decline in U.S. healthcare quality. Journal of Hospital Management and Health Policy [Internet]. 2020 [cited 2020 Sep 6];4:1- 8. doi:10.21037/jhmhp.2020.01.01

22. Pellegrino, ED. The philosophy of medicine reborn: a Pellegrino reader [Internet]. Notre Dame: University of Notre Dame Press; 2008 [cited 2020 Sep 12]. Available from JSTOR: www.jstor.org/stable/j.ctvpj7fgp

23. Tomes, N. Remaking the American patient: how Madison Avenue and modern medicine turned patients into con- sumers [Internet]. North Carolina: University of North Carolina Press; 2016 [cited 2020 Sep 10]. Available from JSTOR: https://www.jstor.org/stable/10.5149/9781469622781_tomes 24. Vento S, Cainelli F, Vallone A. Defensive medicine: it is time to finally slow down an epidemic. World J Clin Cases [Internet]. 2018 [cited 2020 Sep 14];6(11):406-9. doi:10.12998/wjcc.v6.i11.406

25. He ZX, Lang JH. Our thoughts on medicine and philosophy. Chin Med J [Internet]. 2017 [cited 2020 Sep 11];130(3):253-5. doi:10.4103/0366-6999.198936

26. Hajar R. History of medicine timeline. Heart Views [Internet]. 2015 [cited 2020 Sep 10];16(1):43-5. doi:10.4103/1995705X.153008

27. Kleisiaris CF, Sfakianakis C, Papathanasiou IV. Health care practices in ancient Greece: the Hippocratic ideal. J Med Ethics Hist Med [Internet]. 2014 [cited 2020 Sep 10];7:6. Available from NCBI: https://www.ncbi.nlm.nih.gov/pmc/articles/PMC4263393/

28. Zahir II. Hippocrates: philosophy and medicine. ESJ [Internet]. 2016 [cited 2020 Sep 12];12(26):199. doi:10.19044/esj.2016.v12n26p199

29. Pigeaud J. The triumph of dualism in ancient psychopathology. Journal of Psychology \& Psychotherapy [Internet]. 2015 [cited 2020 Sep 11];5(3):1-7. doi:10.4172/2161-0487.1000184

30. Pellegrino ED. Toward a reconstruction of medical morality. Am J Bioeth [Internet]. 2006 [cited 2020 Sep 12];6(2):65-71. doi:10.1080/15265160500508601

31. Veatch RM. How philosophy of medicine has changed medical ethics. J Med Philos [Internet]. 2006 [cited 2020 Sep 12];31(6):585600. doi:10.1080/03605310601009315

32. Marcum JA. Humanizing modern medicine: an introductory philosophy of medicine [Internet]. Philosophy and Medicine, vol 99. Dordrecht: Springer Netherlands; 2008 [cited 2020 Sep 11]. Available from Springer (with access): https://link-springercom.proxy3.library.mcgill.ca/book/10.1007\%2F978-1-4020 $-6797-6$

33. Telles JL, Schramm FR. Paradigm shift, metamorphosis of medical ethics, and the rise of bioethics. Cadernos de Saúde Pública [Internet]. 1999 Feb [cited 2020 Sep 13];15(1):15-25. doi:10.1590/S0102-311X1999000500003

34. Pellegrino ED. Humanism and the physician. Knoxville: University of Tennessee Press; 1979. In: Paradigm shift, metamorphosis of medical ethics, and the rise of bioethics. Cadernos de Saúde Pública [Internet]. 1999 Feb [cited 2020 Sep 26];15(1):1525. doi:10.1590/S0102-311X1999000500003

35. Thibault GE. Humanism in Medicine. Academic Medicine [Internet]. 2019 [cited 2020 Sep 27];94:1074-7. doi:10.1097/ACM.0000000000002796 